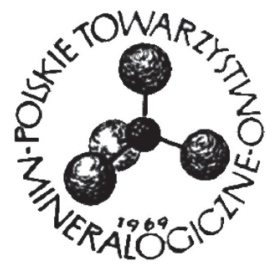

Editorial

\title{
Third Scientific and Technical Conference "Minerals Sorbents", Raw Materials, Power Engineering, Environmental Protection, Modern Technologies, 18-19 September 2017, Cracow
}

Interest in mineral sorbents is growing steadily in terms of both scientific research and the development of the national economy. This is in response to a growing interest in clean manufacturing technologies based on the use of mineral sorbents, and is related to the current issues of environmental protection, which are receiving significant attention both in the European Union and the national legislation. The price for the technical progress and economic development of the $20^{\text {th }}$ century was environmental pollution. In the $21^{\text {st }}$ century, modern approaches based on mineral sorbent technologies are an opportunity for the economic development of our country and for increasing the competitiveness of Polish industry on the world markets, while improving environmental conditions. These issues address the challenges facing our country in terms of protecting the environment, as well as the rational use of natural resources in the creation of modern economies and the development of industry. From the point of view of the national economy, it is important to create our own innovative production technologies that will increase the competitiveness of Polish industry in the world market. To meet these challenges, tight cooperation between science and industry is needed, and thus study of the properties and use of mineral sorbents is important.

The great interest in mineral sorbents by modern science and industry is due to their particular properties, of which the cognition is interdisciplinary. The interaction of sorbents with organic and inorganic substances is the subject of a great number of publications, patents and industrial practices. These effects are fueled by technological progress, increasing demand for ever more efficient and cost-effective technologies, while enhancing research capacity to determine the mineral and chemical composition of sorbents, as well as their structure and texture. The second group of reasons for developing interest in sorbents is the progressive threat and degradation of the environment, which demands the search for new ways and means of reducing the impact of industry.

We present an issue containing articles that were presented at the Third Scientific and Technical Conference "Minerals Sorbents", Raw Materials, Power Engineering, Environmental Protection, Modern Technologies, which took place on 18-19 September 
2017 in Cracow. The conference was a great forum for exchanging experiences, presenting the latest research achievements of the country's leading scientific units to the representatives of the key industry sectors whose production technologies are based on the use of mineral sorbents.

Tomasz Bajda

Guest Editor

Chair of the $3^{\text {rd }}$ Conference

Minerals Sorbents 2017 